\title{
A utilização de glossários terminológicos no processo de ensino e aprendizagem de estudantes surdos no Ensino Superior: uma revisão de literatura
}

The use of terminological glossaries in the teaching and learning process of deaf students in Higher Education: a literature review

El uso de glosarios terminológicos en el proceso de enseñanza y aprendizaje de estudiantes sordos en la Educación Superior: una revisión de la literatura

Mariana Damião Farias

Mestranda na Universidade Federal do Rio Grande do Norte, Natal, RN, Brasil

E-mail: mariannadamiao@gmail.com ORCID: https://orcid.org/0000-0002-4522-1072

Flávia Roldan Viana

Professora doutora da Universidade Federal do Rio Grande do Norte, Natal, RN, Brasil

E-mail: flaviarviana.ufrn@gmail.com ORCID: https://orcid.org/0000-0002-7289-4512

Recebido em 16 de abril de 2021

Aprovado em 24 de setembro de 2021

Publicado em 29 de outubro de 2021

\section{RESUMO}

Esta revisão de literatura teve como objetivo identificar evidências científicas sobre o uso de glossários terminológicos no ensino e aprendizagem de estudantes surdos no Ensino Superior. A revisão analisou 23 publicações acadêmicas selecionadas, sendo 16 dissertações e 07 teses, publicadas entre os anos de 2011 e 2020, das bases de dados BDTD, SciELO, CAPES, ERIC, REDALYC e Repositório Digital Gallaudet University, a partir das palavras-chave: glossários terminológicos, Libras, educação bilíngue e estudantes surdos, no ínterim de março a junho de 2020, nos idiomas português, inglês e espanhol. As informações foram agrupadas nas categorias temáticas: 1. Processo de ensino e aprendizagem do estudante surdo; 2. Educação Bilíngue de Surdos no Ensino Superior; e 3. Glossários Terminológicos em Libras. Não há, ao menos no material coletado para este estudo, pesquisas empreendidas em dissertações e teses a respeito da utilização do glossário no processo de ensino e aprendizagem de estudantes surdos no Ensino Superior, o que comprova a originalidade, relevância e necessidade de realização de pesquisas nesta temática, tendo em vista que trará valiosas contribuições para um escopo do conhecimento científico parcamente explorado até este momento.

Palavras-chave: Glossários terminológicos; Estudantes surdos; Ensino superior.

\section{ABSTRACT}

This literature review aimed to identify scientific evidence on the use of terminological glossaries in the teaching and learning of deaf students in Higher Education. The review analyzed 23 selected academic publications, including 16 dissertations and 7 theses, 
http://dx.doi.org/10.5902/1984686X65313

published between the years 2011 and 2020, from the databases BDTD, SciELO, CAPES, ERIC, REDALYC and Gallaudet University Digital Repository, based on the keywords: terminological glossaries, Libras, bilingual education and deaf students, from March to June 2020, in Portuguese, English and Spanish. The information was grouped into the thematic categories: 1. The deaf student's teaching and learning process; 2. Bilingual Education for the Deaf in Higher Education; and 3. Terminology Glossaries in Libras. There is not, at least in the material collected for this study, research undertaken in dissertations and theses regarding the use of the glossary in the teaching and learning process of deaf students in Higher Education, which proves the originality, relevance and need for research in this theme, bearing in mind that it will bring valuable contributions to a scope of scientific knowledge poorly explored up to this moment.

Keywords: Terminological Glossaries; Deaf students; Higher education.

\section{RESUMEN}

Esta revisión de la literatura tuvo como objetivo identificar evidencia científica sobre el uso de glosarios terminológicos en la enseñanza y el aprendizaje de estudiantes sordos en Educación Superior. La revisión analizó 23 publicaciones académicas seleccionadas, incluyendo 16 disertaciones y 7 tesis, publicadas entre los años 2011 y 2020, de las bases de datos BDTD, SciELO, CAPES, ERIC, REDALYC y Repositorio Digital Gallaudet University, a partir de las palabras clave glosarios terminológicos, Libras, educación bilingüe y estudiantes sordos, de marzo a junio de 2020, en portugués, inglés y español. La información se agrupa en las categorías temáticas: 1. El proceso de enseñanza y aprendizaje del alumno sordo; 2. Educación bilingüe para sordos en la educación superior; y 3. Glosarios de terminología en Libras. No existe, al menos en el material recogido para este estudio, investigaciones realizadas en disertaciones y tesis sobre el uso del glosario en el proceso de enseñanza y aprendizaje de los estudiantes sordos en la Educación Superior, lo que demuestra la originalidad, pertinencia y necesidad de investigación en este tema, teniendo en cuenta que aportará valiosos aportes a un ámbito de conocimiento científico poco explorado hasta el momento.

Palabras clave: Glosarios terminológicos; Estudiantes sordos; Educación superior.

\section{Introdução}

A criação do curso de Licenciatura em Letras Libras foi, inquestionavelmente, um marco para a comunidade surda brasileira. Segundo Quadros $(2014$, p. 10), a primeira turma do curso surgiu no ano de 2006, na Universidade Federal de Santa Catarina, daqui por diante UFSC, um ano depois de sancionado o Decreto $n^{\circ} 5.626 / 2005$, que regulamentou a Lei $n^{\circ}$ 10.436/2002, mais conhecida como Lei de Libras.

$\mathrm{Na}$ Lei de Libras (BRASIL, 2002), a Libras é reconhecida como uma língua, um sistema linguístico de natureza visual-motora, com estrutura gramatical própria, oriundo de comunidades de pessoas surdas do Brasil. Esta definição e este reconhecimento oficial 
http://dx.doi.org/10.5902/1984686X65313

foram subsidiados em pesquisas de caráter linguístico sobre o status da Libras como língua natural, iniciadas, a nível nacional, na década de 1990 pela professora e linguista Lucinda Ferreira-Brito (1995), sendo dada continuidade por Ronice Quadros \& Lodenir Karnopp (2004), Tanya Felipe (2006) e etc., para citar apenas alguns nomes relevantes. (GRASSI; ZANONI; VALENTIN, 2011, p. 59; HARRISON, 2013, p. 31).

Em março de 2007, de acordo com Nembri (2011, p. 9), começou a funcionar o Curso Bilíngue de Pedagogia, na instituição referência nacional no campo da surdez, o Instituto Nacional de Educação de Surdos (INES), com vagas para 60 estudantes - a primeira turma contou com 12 estudantes surdos e 48 estudantes ouvintes.

O surgimento do curso de Letras/Libras e do Curso Bilíngue de Pedagogia no INES representou uma valiosa conquista para os cidadãos surdos brasileiros, pois estimulou o aumento de acesso de estudantes surdos ao ensino superior. De acordo com Quadros e Stumpf (2014, p. 13),

o ingresso de surdos no ensino superior era muito baixo $(0,94 \%)$ em comparação aos ouvintes (17,8\%), mesmo assim se percebeu uma vertiginosa inserção dos surdos neste sistema de ensino no período de 2003 a 2005 [...], um aumento de $705 \%$ de surdos nas universidades brasileiras.

A expansão nacional do curso de Licenciatura em Letras Libras deu-se através do Plano Viver Sem Limites, instituído pelo Decreto $n^{\circ}$ 7.612, no dia 17 de novembro de 2011, ou seja, cinco anos depois da criação do curso na UFSC, já tendo inclusive a primeira turma formada. Com o intuito de ofertar e assegurar a educação bilíngue para os cidadãos surdos, o referido plano mobilizou o surgimento do curso nas 26 capitais estaduais e no Distrito Federal (BRASIL, 2011).

O acréscimo significativo no ingresso de membros da comunidade surda nas universidades, massivamente nos cursos de Letras/Libras, gerou uma mudança na realidade vivenciada até então por estas pessoas e, consequentemente, na comunidade como um todo, pois passaram a ter acesso ao conhecimento científico das mais distintas áreas do conhecimento. (FARIA-NASCIMENTO, 2009, p. 3).

Nos últimos anos, em detrimento a este acesso massivo, o número de glossários terminológicos de Libras no Brasil cada vez mais vem sendo ampliado, sendo utilizado como um instrumento de apoio de estudantes surdos e ouvintes, visto que, de acordo com Camargo (2018, p. 15), a ausência de sinais-termos correspondentes para termos específicos de uma determinada área do saber é um obstáculo para o entendimento do aluno surdo na sala de aula. No que diz respeito ao processo de ensino/aprendizagem 
http://dx.doi.org/10.5902/1984686X65313

destes estudantes, Nóbrega (2017) constatou que o desenvolvimento de glossários "é de suma importância, pois assim os alunos surdos terão melhor aprendizagem nas disciplinas".

Nesse contexto, o presente estudo surgiu da necessidade de investigar como se dá a utilização de glossários terminológicos no processo de ensino e aprendizagem de estudantes surdos no Ensino Superior. Sendo assim, a proposta recai sobre reflexões acerca da identificação dos processos de produção e utilização de glossários terminológicos em Libras, da caracterização dos glossários terminológicos em Libras disponíveis para uso no Ensino Superior e da investigação dos aspectos em que o uso dos glossários terminológicos em Libras favorece o processo de ensino e aprendizagem de estudantes surdos.

\section{Método}

Neste estudo, elaboramos a revisão de literatura com a intenção de realizar um levantamento de estudos relacionados ao uso de glossários terminológicos no processo de ensino e aprendizagem de estudantes surdos no Ensino Superior, para situar a presente pesquisa na literatura existente neste campo do saber.

Noronha e Ferreira (2000, p. 191) definem revisões de literatura como estudos que analisam a produção bibliográfica em determinada área temática ou objeto de estudo, dentro de um recorte de tempo, fornecendo uma visão geral ou um relatório do estado da arte sobre um tópico específico, evidenciando novas idéias, métodos, subtemas que têm recebido maior ou menor ênfase na literatura selecionada.

Desse modo, no sentido de delimitar e caracterizar o objeto de estudo, organizamos a revisão de literatura em três conceitos coadjuvantes que envolvem o objeto de investigação. Portanto, as três conceituações, agrupadas conforme a proximidade de seus objetos de pesquisa e com o intuito de explanar didaticamente os achados, são as seguintes: 1. Processo de ensino e aprendizagem do estudante surdo; 2. Educação Bilíngue de Surdos no Ensino Superior; e 3. Glossários Terminológicos em Libras.

No ínterim dos meses de março a julho de 2020, realizamos a coleta de dados para este estado da arte. As buscas se deram em portais científicos nacionais e internacionais: SciELO - Scientific Eletronic Library Online, BDTD - Biblioteca Digital Brasileira de Teses e Dissertações, Portal de Periódicos da CAPES - Coordenação de Aperfeiçoamento de Pessoal de Nível Superior, ERIC - Education Resources Information Center, REDALYC Red de Revistas Científicas de América Latina y el Caribe, España y Portugal e no 
http://dx.doi.org/10.5902/1984686X65313

Repositório Digital da Gallaudet University, única universidade do mundo cujos programas são desenvolvidos para pessoas surdas.

Os descritores utilizados para fazer as buscas foram quatro palavras-chave desta pesquisa: Glossários Terminológicos. Libras. Educação Bilíngue. Estudantes Surdos. Também foi utilizado o descritor Língua de Sinais como uma variação do descritor Libras, para possibilitar um maior encontro de dados. Não foi utilizada a palavra-chave Ensino e Aprendizagem como um dos descritores por inferir que o uso das palavras-chave Educação Bilíngue e Estudantes Surdos já contemplariam o encontro de pesquisas sobre ensino e aprendizagem. Foram feitas combinações destes descritores nas buscas avançadas dos portais, sendo a cada dois descritores ou a cada três descritores, de acordo com as possibilidades do sistema de busca avançada de cada plataforma.

Para o recorte temporal, escolhemos contemplar as publicações realizadas entre os anos de 2011 e 2020, por percebemos que duas publicações relevantes para a temática deste estudo foram publicadas no ano de 2011 - a dissertação de Castro Júnior, pioneira nos estudos na área de Terminologia de Libras realizados na Universidade de Brasília, referência nacional na questão, e a dissertação de Nembri, a qual trata sobre o Curso Bilíngue de Pedagogia do INES - Instituto Nacional de Educação de Surdos, o primeiro Curso Bilíngue para surdos do Brasil.

Além deste fato, o estabelecimento de um recorte temporal maior do que o tradicionalmente efetuado para as pesquisas stricto sensu, abarcando os últimos cinco anos de publicação, se deu também em virtude do pouco volume de trabalhos realizados na área entre os anos de 2016 a 2020, o que ressalta a relevância de se ter pesquisas atualizadas neste campo do conhecimento científico.

Doravante, estabelecemos os critérios de inclusão e de exclusão. Os critérios de inclusão delimitados foram: dissertações e teses, publicadas a partir do ano de 2011, com duas palavras-chave ou mais em comum com a pesquisa. Já os critérios de exclusão foram: artigos publicados em periódicos, dissertações e teses publicadas antes do ano de 2011 , com menos de duas palavras-chave em comum com a pesquisa.

\section{Resultados}

Na busca empreendida na plataforma do SciELO, o qual permite a combinação de até três descritores, foi realizada primeiramente com os descritores Educação Bilíngue AND Libras OR Língua de Sinais, a qual deu um resultado de 32 artigos. Em sequência, foi feita 
http://dx.doi.org/10.5902/1984686X65313

a procura com os descritores Glossários Terminológicos AND Libras OR Língua de Sinais, que rendeu um índice de 166 resultados, totalizando 198 artigos encontrados nesta plataforma.

Para a busca no site da BDTD, o qual também permite a utilização de até três descritores, de início pesquisou-se com os descritores Educação Bilíngue E Estudantes Surdos E Libras, com o retorno de 214 publicações acadêmicas. Depois, em uma nova investigação, utilizou-se os descritores Glossários Terminológicos E Língua de Sinais E Libras, a qual trouxe 15 pesquisas, somando 229 dissertações e teses encontradas neste site.

A busca no Portal de Periódicos da CAPES, o qual permite o uso de até dois descritores, foi empreendido um número maior de pesquisas, no intuito de levantar o máximo de dados possível. Começou-se a primeira pesquisa com os descritores Glossários Terminológicos AND Libras, resultante ínfimo de 02 achados. A segunda averiguação foi com os descritores Educação Bilíngue AND Libras, com 132 artigos encontrados. Na terceira procura, utilizou-se os descritores Educação Bilíngue AND Estudantes Surdos, com resposta de 44 publicações em periódicos. O quarto e último rastreio se valeu dos descritores Glossários terminológicos AND Língua de Sinais, com o retorno de 04 artigos científicos achados, o que faz o somatório de 182 trabalhos encontrados neste portal.

O repositório digital da Gallaudet University e as plataformas ERIC e REDALYC não forneceram publicações concernentes com o objeto deste estudo em nenhuma das tentativas de mesclas realizadas com os descritores traduzidos para a língua inglesa, no caso dos dois primeiros, e com descritores traduzidos para a língua espanhola, no caso do último.

Somando-se a literatura encontrada no SciELO, na BDTD e no Portal da CAPES, a partir dos processos detalhados anteriormente, totalizam-se 609 pesquisas. Deste montante, inicialmente selecionamos 43 artigos e 37 teses/dissertações, utilizando unicamente como critério de inclusão a aproximação temática dos trabalhos com o objeto de estudo desta dissertação.

Depois de estabelecido o recorte temporal e delimitados os critérios de inclusão e exclusão, chegamos ao total de 23 publicações acadêmicas selecionadas, sendo 16 dissertações e 07 teses. Abaixo, seguem os dados iniciais das produções escolhidas para compor a revisão de literatura. 
http://dx.doi.org/10.5902/1984686X65313

Quadro 1 - Levantamento de dissertações e teses para a revisão de literatura

(continua)

\begin{tabular}{|c|c|c|c|}
\hline AUTOR & TíTULO & $\begin{array}{c}\text { TIPO DE } \\
\text { PUBLICAÇÃO/ANO }\end{array}$ & ORIGEM \\
\hline $\begin{array}{c}\text { CASTRO } \\
\text { JúNOR, G. de. }\end{array}$ & $\begin{array}{c}\text { Variação linguística em Língua } \\
\text { de Sinais Brasileira- foco no } \\
\text { léxico }\end{array}$ & Dissertação/2011 & $\begin{array}{l}\text { Universidade } \\
\text { de Brasília }\end{array}$ \\
\hline NEMBRI, A. G. & $\begin{array}{l}\text { O cotidiano escolar do Curso } \\
\text { Bilíngue de Pedagogia do } \\
\text { Instituto Nacional de Educação } \\
\text { de Surdos - INES: um olhar } \\
\text { avaliativo }\end{array}$ & Dissertação/2011 & $\begin{array}{l}\text { Fundação } \\
\text { Cesgranrio }\end{array}$ \\
\hline BARROS, R. L. & $\begin{array}{c}\text { Política linguística: a } \\
\text { terminologia da Libras como } \\
\text { veículo de cultura em concursos } \\
\text { públicos }\end{array}$ & Dissertação/2012 & $\begin{array}{l}\text { Universidade } \\
\text { de Brasília }\end{array}$ \\
\hline $\begin{array}{l}\text { LORTHIOIS, A. } \\
\text { A. M. }\end{array}$ & $\begin{array}{c}\text { Ações de uma professora- } \\
\text { pesquisadora no processo de } \\
\text { construção de conceitos em } \\
\text { língua de sinais numa escola } \\
\text { bilíngue para Surdos }\end{array}$ & Dissertação/2012 & $\begin{array}{c}\text { Pontifícia } \\
\text { Universidade } \\
\text { Católica de São } \\
\text { Paulo }\end{array}$ \\
\hline RIBEIRO, D. P & $\begin{array}{l}\text { Glossário bilíngue da língua de } \\
\text { sinais brasileira: Criação de } \\
\text { sinais dos termos da música }\end{array}$ & Dissertação/2013 & $\begin{array}{l}\text { Universidade } \\
\text { de Brasília }\end{array}$ \\
\hline BOSCO, D. C. & $\begin{array}{l}\text { Educação bilíngue para surdos: } \\
\text { práticas discursivas em tempos } \\
\text { de inclusão }\end{array}$ & Dissertação/2014 & $\begin{array}{l}\text { Universidade } \\
\text { Estadual } \\
\text { Paulista }\end{array}$ \\
\hline $\begin{array}{c}\text { CASTRO } \\
\text { JÚNOR, G. de. }\end{array}$ & Projeto Varlibras & Tese/2014 & $\begin{array}{l}\text { Universidade } \\
\text { de Brasília }\end{array}$ \\
\hline $\begin{array}{c}\text { CosTA, H. A. } \\
\text { de C. }\end{array}$ & $\begin{array}{c}\text { Políticas públicas na educação } \\
\text { dos surdos: O que se diz, o que } \\
\text { se faz, o que os surdos } \\
\text { querem... }\end{array}$ & Dissertação/2014 & $\begin{array}{l}\text { Pontifícia } \\
\text { Universidade } \\
\text { Católica de } \\
\text { Minas Gerais }\end{array}$ \\
\hline $\begin{array}{c}\text { DOUETTES, B. } \\
\text { B. }\end{array}$ & $\begin{array}{c}\text { A tradução na criação de sinais- } \\
\text { termos religiosos em Libras e } \\
\text { uma proposta para organização } \\
\text { de glossário terminológico } \\
\text { semibilíngue }\end{array}$ & Dissertação/2015 & $\begin{array}{l}\text { Universidade } \\
\text { Federal de } \\
\text { Santa Catarina }\end{array}$ \\
\hline $\begin{array}{c}\text { LOBATO, M. J. } \\
\mathrm{S}\end{array}$ & $\begin{array}{c}\text { Educação bilíngue no contexto } \\
\text { escolar inclusivo: a construção } \\
\text { de um glossário em Libras e } \\
\text { Língua Portuguesa na área de } \\
\text { matemática }\end{array}$ & Dissertação/2015 & $\begin{array}{l}\text { Universidade } \\
\text { Federal do Rio } \\
\text { Grande do } \\
\text { Norte }\end{array}$ \\
\hline $\begin{array}{l}\text { OLIVEIRA, J. S. } \\
\text { de }\end{array}$ & $\begin{array}{c}\text { Análise descritiva da estrutura } \\
\text { querológica de unidades } \\
\text { terminológicas do glossário } \\
\text { Letras-Libras }\end{array}$ & Tese/2015 & $\begin{array}{l}\text { Universidade } \\
\text { Federal de } \\
\text { Santa Catarina }\end{array}$ \\
\hline FELTEN, E. F. & $\begin{array}{c}\text { Glossário sistêmico bilíngue } \\
\text { português-Libras de termos da } \\
\text { História do Brasil }\end{array}$ & Dissertação/2016 & $\begin{array}{l}\text { Universidade } \\
\text { de Brasília }\end{array}$ \\
\hline $\begin{array}{l}\text { NASCIMENTO, } \\
\text { C. B. do. }\end{array}$ & $\begin{array}{l}\text { Terminografia Língua de Sinais } \\
\text { Brasileira: proposta de glossário } \\
\text { ilustrado semibilíngue do meio } \\
\text { ambiente, em mídia digital }\end{array}$ & Tese/2016 & $\begin{array}{l}\text { Universidade } \\
\text { de Brasília }\end{array}$ \\
\hline
\end{tabular}


http://dx.doi.org/10.5902/1984686X65313

Quadro 1 - Levantamento de dissertações e teses para a revisão de literatura

(conclusão)

\begin{tabular}{|c|c|c|c|}
\hline AUTOR & TÍTULO & $\begin{array}{c}\text { TIPO DE } \\
\text { PUBLICAÇÃO/ANO }\end{array}$ & ORIGEM \\
\hline $\begin{array}{c}\text { CARDOSO, V. } \\
\text { R. }\end{array}$ & $\begin{array}{c}\text { Terminografia da Língua } \\
\text { Brasileira de Sinais. Glossário } \\
\text { de nutrição }\end{array}$ & Dissertação/2017 & $\begin{array}{c}\text { Universidade de } \\
\text { Brasília }\end{array}$ \\
\hline $\begin{array}{l}\text { KUMADA, K. } \\
\text { M. O }\end{array}$ & $\begin{array}{l}\text { Acesso do surdo a cursos } \\
\text { superiores de formação de } \\
\text { professores de Libras em } \\
\text { instituicões federais }\end{array}$ & Tese/2017 & $\begin{array}{l}\text { Universidade de } \\
\text { São Paulo }\end{array}$ \\
\hline VIEIRA, C. R. & $\begin{array}{l}\text { Educação bilíngue para surdos: } \\
\text { reflexões a partir de uma } \\
\text { experiência pedagógica }\end{array}$ & Tese/2017 & $\begin{array}{l}\text { Universidade de } \\
\text { São Paulo }\end{array}$ \\
\hline TUXI, P. & $\begin{array}{c}\text { A terminologia na língua de } \\
\text { sinais brasileira: proposta de } \\
\text { organização e de registro de } \\
\text { termos técnicos e } \\
\text { administrativos do meio } \\
\text { acadêmico em glossário } \\
\text { bilíngue. }\end{array}$ & Tese/2017 & $\begin{array}{c}\text { Universidade de } \\
\text { Brasília }\end{array}$ \\
\hline ABATI, F. R & $\begin{array}{l}\text { Proposta de glossário bilíngue: } \\
\text { terminologia dos } \\
\text { "procedimentos de tradução" em } \\
\text { Língua de Sinais Brasileira }\end{array}$ & Dissertação/2018 & $\begin{array}{c}\text { Universidade de } \\
\text { Brasília }\end{array}$ \\
\hline BAGGIO, A. L. & $\begin{array}{l}\text { Reconhecimento de línguas de } \\
\text { sinais e educação de surdos no } \\
\text { Brasil e na Suécia }\end{array}$ & Dissertação/2018 & $\begin{array}{l}\text { Universidade } \\
\text { Federal de São } \\
\text { Carlos }\end{array}$ \\
\hline $\begin{array}{c}\text { MARTINS, F. } \\
\text { C. }\end{array}$ & $\begin{array}{l}\text { Terminologia da Libras: coleta e } \\
\text { registro de sinais-termo da área } \\
\text { de psicologia }\end{array}$ & Tese/2018 & $\begin{array}{l}\text { Universidade } \\
\text { Federal de Santa } \\
\text { Catarina }\end{array}$ \\
\hline $\begin{array}{l}\text { SANTOS, A. } \\
\text { N. M. dos. }\end{array}$ & $\begin{array}{l}\text { A língua brasileira de sinais na } \\
\text { educação de surdos: língua de } \\
\text { instrução e disciplina curricular }\end{array}$ & Dissertação/2018 & $\begin{array}{l}\text { Universidade de } \\
\text { São Paulo }\end{array}$ \\
\hline $\begin{array}{l}\text { ATAYDE, S. } \\
\text { T. S. de. }\end{array}$ & $\begin{array}{l}\text { O uso da Libras na matemática } \\
\text { do ensino fundamental: uma } \\
\text { proposta de glossário }\end{array}$ & Dissertação/2019 & $\begin{array}{l}\text { Universidade } \\
\text { Federal de Goiás }\end{array}$ \\
\hline $\begin{array}{l}\text { FRIEDRICH, } \\
\text { M. A. }\end{array}$ & $\begin{array}{c}\text { Glossário em Libras: uma } \\
\text { Proposta de Terminologia } \\
\text { Pedagógica (Português-Libras) } \\
\text { no Curso de Administração da } \\
\text { UFPel }\end{array}$ & Dissertação/2019 & $\begin{array}{l}\text { Universidade } \\
\text { Federal de } \\
\text { Pelotas }\end{array}$ \\
\hline
\end{tabular}

Fonte: Dados da pesquisa (2020).

\section{Discussão}

\section{Processo de ensino e aprendizagem do estudante surdo}

No campo conceitual 1. Processo de ensino e aprendizagem do estudante surdo, dos 23 trabalhos selecionados, 06 se enquadraram nos critérios estabelecidos, sendo 05 dissertações e 01 tese, publicadas entre os anos de 2012 e 2018, sendo quase todas 
http://dx.doi.org/10.5902/1984686X65313

provenientes de universidades paulistas - apenas uma delas veio de uma instituição mineira.

Lorthiois (2012) investigou especificamente o papel do professor na construção de significados em língua de sinais, visto que o tipo de interação entre alunos e professora influencia todo o processo de ensino e aprendizagem. Como resultado, atestou que muitas das ações realizadas pela professora propiciaram a construção de conceitos pelos alunos surdos, inclusive atentando às especificidades linguísticas, educacionais e sociais destes.

Bosco (2014) analisou as contribuições das práticas discursivas na constituição de sujeitos bilíngues, em dois espaços educacionais: uma escola inclusiva com proposição bilíngue e uma escola bilíngue para surdos, utilizando videogravações e o registro escrito de observações das práticas discursivas realizadas em sala de aula.

A pesquisadora concluiu que os dados apontam para a necessidade de ajustes para a oferta de um real ambiente bilíngue, visto que é um espaço que reconhece a especificidade e a diferença linguística do aluno surdo, procurando oferecer uma experiência de escolarização responsável e consistente, permeadas por processos que possam ser positivamente significativos para esse alunado.

Costa (2014) analisou as políticas públicas educacionais para as pessoas surdas na Rede Municipal de Ensino de Belo Horizonte, verificando se a atual política de educação inclusiva atende às reais necessidades educacionais das crianças surdas, na educação infantil e nos anos iniciais do ensino fundamental.

A pesquisa apontou que há necessidade de se repensar as políticas públicas para a educação dos surdos, considerando o ponto de vista, político e educacional, apresentado pela Comunidade Surda, buscando ressignificar o espaço educacional das crianças surdas, assegurando-Ihes o direito à educação que reconheça as diferenças linguísticas, pedagógicas e culturais, ou seja, a oferta de uma educação bilíngue.

A tese de Vieira (2017) refletiu e analisou as práticas pedagógicas construídas a partir de uma proposta assumidamente bilíngue para Educação de Surdos, de uma instituição de ensino reconhecida na grande São Paulo. Entre os achados do estudo, constatou, na proposta bilíngue executada nesta instituição, a preponderância do uso da Libras como língua de comunicação e de instrução, o empoderamento do surdo e de sua identidade, o papel do interlocutor usuário fluente da Libras para a consolidação da língua por parte da criança surda e adultos surdos, o que, para ela, desempenhando o papel de modelo 
http://dx.doi.org/10.5902/1984686X65313

possível de ser seguido por outras instituições de ensino que tenham estudantes surdos matriculados.

Baggio (2018), ao investigar, na perspectiva comparada, os documentos que reconhecem as línguas de sinais no Brasil e na Suécia e ao analisar se os respectivos reconhecimentos contribuíram para o processo educacional dos surdos, comprova que ambos os países percorreram caminhos bem distintos até alcançar o reconhecimento da língua de sinais, com o país europeu tendo legislações amparando a utilização da língua de sinais pelos surdos desde a década de 1980 e a nação sul-americana reconhecendo a Libras como língua da comunidade surda nacional apenas em 2002, mas, sempre com o objetivo de tentar proporcionar uma educação bilíngue aos surdos.

Em sua dissertação, Santos (2018) discute como a língua brasileira de sinais tem sido utilizada e ensinada nas escolas bilíngues para surdos no município de São Paulo, verificando que, nas escolas pesquisadas, a Libras é verdadeiramente língua de instrução e que há garantia do ensino de tal disciplina.

Os achados neste primeiro setor demonstram que a educação bilíngue é o modelo que mais garante um processo de ensino e aprendizagem significativo para os estudantes surdos, por reconhecer e considerar as especificidades linguísticas, educacionais e culturais destes sujeitos, principalmente ao se valer da Libras como língua de instrução em todos os componentes curriculares, propiciar um ensino que valoriza a presença da visualidade e não a ausência da audição e fomentá-la também como língua de interação entre todos os membros da comunidade escolar e como a língua de produção de materiais didáticos para estes educandos.

\section{Educação bilíngue de Surdos no Ensino Superior}

No conceito coadjuvante 2. Educação Bilíngue de Surdos no Ensino Superior, apenas 02 pesquisas de 23 obedeceram aos indicadores, sendo uma dissertação e uma tese, publicadas em 2011 e 2017, respectivamente, com a dissertação advinda do estado do Rio de Janeiro e a tese do estado de São Paulo. O baixo quantitativo de estudos presentes aqui, mesmo levando em consideração o recorte temporal e os critérios de inclusão e de exclusão desta pesquisa, revela que há poucos trabalhos realizados que contemplam esta temática.

A dissertação de Nembri (2011), pesquisador surdo, avaliou a utilização da Libras como instrumento mediador da abordagem bilíngue proposta pelas diretrizes do primeiro 
Curso Superior Bilíngue, no caso, o Curso de Pedagogia, para estudantes ouvintes e surdos, oferecido pelo Instituto Nacional de Educação de Surdos (INES). Ele verificou que, apesar do ineditismo da proposta, a abordagem bilíngue ainda não foi completa e efetivamente contemplada, em função da não utilização plena da Língua de Sinais com língua de instrução e de comunicação no cotidiano escolar.

A pesquisa de doutorado de Kumada (2017) investiga e analisa o acesso dos surdos a cursos superiores de formação de professores de Libras em instituições federais, isto é, a cursos de Pedagogia bilíngue ofertados no INES e cursos de Letras Libras ofertados em todo o país na última década. Os resultados apontaram para um quantitativo ainda escasso de vagas ofertadas nacionalmente para a formação de professores de Libras, sobretudo no segmento que abrange a educação infantil e os anos iniciais do ensino fundamental, que é o do Curso de Pedagogia do INES.

Além disso, os resultados constataram ainda uma grande dificuldade por parte das instituições federais investigadas em: propiciar as condições de acessibilidade durante os processos seletivos, sendo muitas vezes observada a omissão de adequações ou a burocratização no seu deferimento; interpretar a prioridade reservada aos candidatos surdos e a flagrante presença da concepção patológica do surdo ainda muito arraigada nas exigências e nos textos dos editais e provas analisados, e uma visão essencializada das competências linguísticas do sujeito surdo e da noção de identidade.

Os dois estudos problematizam as condições de acesso e permanência apresentadas pelos dois cursos existentes com o modelo de educação bilíngue no Brasil, o Curso de Pedagogia ofertado pelo INES e os cursos de Letras Libras ofertados nas instituições federais de ensino Brasil a fora, com a dissertação de Nembri (2011) enfocando somente no primeiro, talvez pelo pioneirismo da graduação.

Ou seja, apesar de louváveis, as iniciativas empregadas até então na Educação Bilíngue de surdos no Ensino Superior apresentam inúmeras fragilidades e inconsistências, compreendidas pelos pesquisadores como comuns em se tratando do pouco tempo de implantação destes e de terem surgido sem ter um modelo bem-sucedido no qual pudessem se espelhar.

Há de se ressaltar que, talvez em virtude de se haver poucos exemplos de Cursos bilíngues de graduação, embora exista uma boa quantidade de pesquisas sobre a importância e a necessidade de se ter uma educação bilíngue em instituições escolares da educação básica, como bem demonstram as pesquisas detalhadas no conceito anterior, 
http://dx.doi.org/10.5902/1984686X65313

quando se trata de investigar este modelo educacional no Ensino Superior, há um notório decréscimo de produção.

\section{Glossários Terminológicos em Libras}

E, finalmente, na conceituação 3. Glossários Terminológicos em Libras, 15 publicações foram selecionadas, sendo 09 dissertações e 06 teses, o que denota um volume de pesquisas crescente nesta área de conhecimento. Deste montante, 09 estudos, ou seja, 60\% deles, provêm da Universidade de Brasília (UnB), mais precisamente do Centro de Estudos Lexicais e Terminológicos - Centro Lexterm - do Departamento de Linguística, Português e Línguas Clássicas (LIP), com a Prof ${ }^{a}$. Dra. Enilde Faulstich como responsável.

Na dissertação de Castro Júnior (2011), pesquisador surdo, há a investigação das variações linguísticas naturais na Libras e das variações linguísticas que resultam da interferência da Língua Portuguesa na Libras, com os resultados mostrando a ocorrência de variantes e possibilitando a escolha da variante-padrão para cada termo através de diferentes processos linguísticos.

Barros (2012), pesquisadora surda, desenvolveu, na dissertação, aspectos de uma Política Linguística voltada para a Terminologia da Libras, como veículo da cultura em concursos públicos, visto ser esta uma área que ainda não possui uma terminologia, culminando na apresentação de glossário terminológico semibilíngue de Direito Administrativo.

Ribeiro (2013), pesquisadora surda, desenvolveu um léxico bilíngue, com base nos termos que são utilizados numa aula de musicalização, por causa das dificuldades de aprendizagem dos estudantes surdos numa sala de aula de musicalização; a maioria dos professores tem dificuldade de ensinar, não só pela falta de comunicação plena, mas, principalmente, pela falta de sinais próprios dos termos musicais, o que resultou na criação da proposta de um glossário bilíngue com sinais-termo na área de música.

Castro Júnior (2014), agora em pesquisa de doutorado, aplicou o estudo do desenvolvimento da variação linguística na Libras para a criação de um Núcleo de Pesquisa em Variação Regional dos Sinais da Libras - Varlibras, com os objetivos de: i) divulgar os estudos da variação linguística da Libras pautada na educação lexicográfica nos princípios da lexicografia, ii) especificar os elementos que compõe o sinal-termo de modo a 
http://dx.doi.org/10.5902/1984686X65313

compreender os mecanismos de criação e registro do léxico da Libras; iii) contribuir para a divulgação de novas pesquisas nos estudos da variação linguística da Libras.

Douettes (2015), ao perceber a ausência de glossários com sinais-termos religiosos em Libras, apresentou uma proposta para a elaboração de um glossário semibilíngue de termos religiosos bíblicos, com base nos sinais-termos coletados em três manuais de Libras publicados no Brasil, um de cada religião pesquisada: Católica, Evangélica (Batista) e Testemunhas de Jeová.

Lobato (2015), em pesquisa elaborada no mestrado profissional, constatando as dificuldades dos professores e alunos surdos em abordar os conteúdos curriculares de matemática nas escolas municipais de Natal, conhecidas como complexos bilíngues de referência para surdos, construiu uma proposta de glossário que possibilitou a representação de termos matemáticos em Língua Brasileira de Sinais (Libras) e em Língua Portuguesa. A autora apontou a relevância da elaboração deste glossário como material didático bilíngue, mostrando que este facilita a utilização da Libras pelo professor e a possiblidade de melhorias no processo de aprendizagem dos alunos surdos, pois o glossário serviu como suporte de consulta sobre a tradução em Libras de termos da matemática para o docente e sobre o significado destes termos para os estudantes surdos, desconhecidos para estes até então. Dessa forma, a pesquisa concluiu que o uso do glossário em sala de aula resolveu entraves linguísticos, que estavam desencadeando prejuízos educacionais para os estudantes com surdez, favorecendo uma melhor qualidade no ensino e aprendizagem destes educandos.

A tese de Oliveira (2015) identifica e descreve os elementos querológico-morfológicos de unidades terminológicas em Libras com base no Glossário Letras-Libras, averiguando quais são as características descritivas dos sinais coletados no Glossário Letras-Libras ou quais são os elementos querológicos e morfológicos das unidades lexicais do Glossário Letras-Libras, sendo o glossário utilizado como fonte de dados tanto para validar proposições apresentadas na literatura da área quanto para questionar e a contestar outras.

Felten (2016) sistematizou termos da História do Brasil do português e propôss a criação de sinais-termo correspondentes na Libras, por evidenciar que a falta de termos de especialidade na Libras dificulta o trabalho profissional do professor e intérprete de Libras e também a aprendizagem dos alunos surdos, o que resultou no Glossário Sistêmico Bilíngue Português - Libras de termos da História do Brasil, com 14 sinais-termo. 
http://dx.doi.org/10.5902/1984686X65313

Nascimento (2016) desenvolveu um glossário ilustrado semibilíngue da área de Meio Ambiente, com vistas à escolarização de surdos das séries finais do Ensino Fundamental, o Glossário llustrado do Meio Ambiente Libras-Português - GIMALP, com um modelo terminográfico online que apresenta três mecanismos de acesso aos verbetes: pela LSB, pela LP e pela ilustração.

Cardoso (2017) criou uma proposta de glossário bilíngue Língua Brasileira de Sinais (Libras)/ Português em nutrição, representado por sinais-termo de repertórios lexicográficos já existentes na língua de sinais, porém, que estão destinados a outras áreas, de modo a contribuir e atender as necessidades dos usuários da Libras.

Visto que os espaços sociais e acadêmicos em cursos de graduação e pós-graduação da Universidade de Brasília estão cada vez mais ocupados pelos alunos surdos e a ausência de sinais-termo na área acadêmica e administrativa, Tuxi (2017), em pesquisa de doutorado, criou uma proposta de organização e registro de glossário bilíngue, Língua Portuguesa - LP e Língua de Sinais Brasileira - LSB com 38 sinais-termo e a inovação do uso do QR Code e de videoguias como instrumento de acessibilidade e interação para o surdo, inserido no espaço acadêmico.

Entretanto, Abati (2018) verificou a escassez de glossários ou trabalhos terminográficos em língua de sinais sobre procedimentos de tradução para TILS Tradutores Intérpretes de Libras de discentes surdos universitários. Para tentar solucionar a problemática, elaborou um glossário bilíngue com 15 termos referentes aos procedimentos de tradução, em Língua Portuguesa e em Libras.

A tese de Martins (2018), pesquisadora surda, documentou os 145 sinais-termo em Libras que são relacionados à área da Psicologia e utilizados por psicólogos surdos, visando aumentar a representatividade dos sinais de uso comum entre psicólogos na próxima edição do Glossário Libras UFSC - Universidade Federal de Santa Catarina, bem como auxiliar os discentes, tradutores/intérpretes, docentes de Libras e profissionais da área.

Ao se deparar com as dificuldades encontradas por professores intérpretes em repassar o conteúdo matemático para o aluno surdo de forma facilitadora de seu aprendizado, a dissertação escrita por Athayde (2019), a nível de mestrado profissional, apresenta uma proposta de construção de um glossário em Libras, investigando os sinais disponíveis para possibilitar aos alunos surdos do $8^{\circ}$ ano melhorias no processo de ensino e aprendizagem de Matemática. O glossário criado foi usado pelos alunos surdos e ofertado 
http://dx.doi.org/10.5902/1984686X65313

à escola como material de consulta e apoio para os professores, intérpretes e alunos dos anos seguintes. A pesquisa constatou que esta utilização do glossário no chão da escola resultou em um ensino mais efetivo e em um acréscimo da compreensão destes estudantes surdos sobre os conteúdos matemáticos, o que impactou diretamente na qualidade da aprendizagem deste público.

Friedrich (2019) propôs um glossário voltado à área da administração, visando auxiliar os acadêmicos surdos, intérpretes de Libras e profissionais da área a buscar e acessar os novos conceitos e sinais. O produto final foi criado: glossário em Libras dos sinais-termo do curso de Administração da Universidade Federal de Pelotas, totalizando 102 sinais-termo de 25 palavras.

Neste grupo de pesquisas do terceiro conceito, inicialmente há de se ressaltar a maior presença de surdos como produtores de conteúdo científico, promovidas pela UnB e, em menor grau, pela UFSC, com boa parte dos trabalhos realizados em instituições federais de ensino, na tentativa de resolução de problemáticas surgidas nestes locais.

Todos os trabalhos selecionados trazem propostas de criação de glossários terminológicos com o objetivo de facilitar o processo de ensino e aprendizagem de estudantes surdos. Entretanto, quase todos postulam que a facilidade deste processo se dará em virtude da presença dos sinais-termo presentes nestes glossários, isto é, o glossário está sendo visto apenas como um depósito de itens lexicais e está apenas nestes léxicos a potencialidade de alavancar o desempenho educacional.

Com exceção dos trabalhos de Lobato (2015) e Athayde (2019), ambos advindos do mestrado profissional, não há, ao menos no material coletado para este estudo, pesquisas empreendidas em dissertações e teses a respeito da utilização do glossário como um material didático no processo de ensino e aprendizagem de estudantes surdos.

\section{Considerações finais}

O levantamento de dados realizado para a composição desta revisão de literatura, com o total de 23 publicações acadêmicas selecionadas, sendo 16 dissertações e 07 teses, publicadas entre os anos de 2011 e 2020, evidenciou uma multiplicidade de resultados nos trabalhos escolhidos e a quase inexistência de pesquisas elaboradas que abarquem 0 objeto de estudo deste trabalho.

Os trabalhos analisados demonstram que o ensino bilíngue, com a Libras como língua de instrução e a Língua Portuguesa sendo utilizada na modalidade escrita, propicia maiores 
http://dx.doi.org/10.5902/1984686X65313

ganhos no processo de ensino e aprendizagem do surdo. No entanto, em se tratando do Ensino Superior, há uma escassez de Cursos de graduação que contemplem esta metodologia educacional e os existentes não estão com estrutura sólida o bastante para ofertar uma formação de qualidade a estes estudantes. Quanto ao uso do glossário como material didático bilíngue na educação de surdos, nos deparamos com um bom quantitativo de exemplares produzidos, sendo que nenhum deles fora utilizado com um viés pedagógico, salvo as exceções das pesquisas empreendidas por Lobato (2015) e Athayde (2018).

Quando enfocamos no objeto de estudo, isto é, na utilização do glossário terminológico no processo de ensino e aprendizagem de estudantes surdos no Ensino Superior, nem os dois trabalhos citados anteriormente contemplam o objeto de estudo desta pesquisa, pois ambos foram desenvolvidos na educação básica, em escolas do Ensino Fundamental.

Portanto, pode-se concluir que o presente estudo comprova a originalidade, relevância e necessidade de realização de pesquisas nesta temática, tendo em vista que trará valiosas contribuições para um escopo do conhecimento científico parcamente explorado até este momento.

\section{Referências}

ABATI, Flávia Rech. Proposta de glossário bilíngue: terminologia dos "procedimentos de tradução" em Língua de Sinais Brasileira. Dissertação (Mestrado). Programa de PósGraduação em Estudos da Tradução. Universidade de Brasília, Brasília, 2018.

ATHAYDE, Suenio Tomáz Spindola de. 0 uso da Libras na matemática do ensino fundamental: uma proposta de glossário. Dissertação (Mestrado). Programa de Mestrado Profissional em Matemática em Rede Nacional, Catalão-GO, Universidade Federal de Goiás, 2019.

BAGGIO, Aline Lucia. Reconhecimento de línguas de sinais e educação de surdos no Brasil e na Suécia. Dissertação (Mestrado). Programa de Pós-Graduação em Educação Especial, São Carlos, Universidade Federal de São Carlos, 2018.

BARROS, Rejane Louredo. Política linguística: a terminologia da Libras como veículo de cultura em concursos públicos. Dissertação (Mestrado). Programa de Pós-Graduação em Linguística, Universidade de Brasília, Brasília, 2012.

BOSCO, Daniella Cristina. Educação bilíngue para surdos: práticas discursivas em tempos de inclusão. Dissertação (Mestrado). Programa de Pós-Graduação em Educação, Universidade Estadual Paulista, Marília, 2014. 
http://dx.doi.org/10.5902/1984686X65313

BRASIL. Decreto lei no 7.612, de 17 de novembro de 2011. Disponível em: http://www.planalto.gov.br/ccivil_03/_ato2011-2014/2011/decreto/d7612.htm. Acesso em: 24 ago. 2019.

BRASIL. Lei no 10.436, de 22 de abril de 2002. Disponível em:

http://www.planalto.gov.br/ccivil_03/Leis/2002/L10436.htm.. Acesso em: 14 out. 2020.

CAMARGO, Morgana Gentlin. Glossário de termos contábeis em Língua brasileira de sinais. Trabalho de Conclusão de Curso. Universidade de Caxias do Sul, Caxias do Sul, 2018. Disponível em:

https://repositorio.ucs.br/xmlui/bitstream/handle/11338/3874/TCC\%20Morgana\%20Gentlin \%20Camargo.pdf?sequence=1\&amp;isAllowed=y. Acesso em: 24. set. 2020.

CARDOSO, Vilma Rodrigues. Terminografia da Língua Brasileira de Sinais. Glossário de nutrição. Dissertação (Mestrado). Programa de Pós-Graduação em Estudos da Tradução. Universidade de Brasília, Brasília, 2017.

CASTRO JÚNIOR, Gláucio de. Variação linguística em Língua de Sinais Brasileira foco no léxico. Dissertação (Mestrado). Programa de Pós-Graduação em Linguística. Universidade de Brasília, Brasília, 2011.

CASTRO JÚNIOR, Gláucio de. Projeto Varlibras. Tese (Doutorado). Programa de PósGraduação em Linguística. Universidade de Brasília, Brasília, 2014.

COSTA, Heliane Alves de Carvalho. Políticas públicas na educação dos surdos: $O$ que se diz, o que se faz, o que os surdos querem... Dissertação (Mestrado). Programa de PósGraduação em Educação, Pontifícia Universidade Católica de Minas Gerais, Belo Horizonte, 2014.

DOUETTES, Breno Barros. A tradução na criação de sinais-termos religiosos em Libras e uma proposta para organização de glossário terminológico semibilíngue. Dissertação (Mestrado). Programa de Pós-Graduação em Estudos da Tradução. Universidade Federal de Santa Catarina, Florianópolis, 2015.

FARIA-NASCIMENTO, Sandra Patrícia. Representações lexicais da Língua de Sinais Brasileira: uma proposta lexicográfica. Tese (Doutorado) - Programa de Pós-Graduação em Lingüística, Universidade de Brasília, Brasília, 2009.

FELTEN, Eduardo Felipe. Glossário sistêmico bilíngue português-Libras de termos da História do Brasil. Dissertação (Mestrado). Programa de Pós-graduação em Linguística, Universidade de Brasília, Brasília, 2016.

FRIEDRICH, Márcio Aurélio. Glossário em Libras: uma Proposta de Terminologia Pedagógica (Português-Libras) no Curso de Administração da UFPel. Dissertação (Mestrado). Programa de Pós-graduação em Letras, Universidade Federal de Pelotas, Pelotas-RS, 2019.

GRASSI, Dayse.; ZANONI, Graziely Grassi; VALENTIN, Silvana Mendonça Lopes. Língua brasileira de sinais: aspectos linguísticos e culturais. Revista Trama, Marechal Cândido Rondon, PR, v. 7, n. 14, jul/dez. 2011, p. 57-68. 
HARRISON, Kathryn Marie Pacheco. Libras: apresentando a língua e suas características. In: LACERDA, C. B. F. de.; SANTOS, L. F. dos. (Org.). Tenho um aluno surdo, e agora? São Carlos: EdUFSCar, 2013, p. 27-36.

KUMADA, Kate Mamhy Oliveira. Acesso do surdo a cursos superiores de formação de professores de Libras em instituições federais. Tese (Doutorado). Programa de Pós-graduação em educação, Universidade de São Paulo, São Paulo, 2017.

LOBATO, Maria José Silva. Educação bilíngue no contexto escolar inclusivo: a construção de um glossário em Libras e Língua Portuguesa na área de matemática. Dissertação (Mestrado). Programa de Pós-Graduação em Ensino de Ciências Naturais e Matemática, Universidade Federal do Rio Grande do Norte, Natal-RN, 2015.

LORTHIOIS, Amandine Alpha Marie. Ações de uma professora-pesquisadora no processo de construção de conceitos em língua de sinais numa escola bilíngue para Surdos. Dissertação (Mestrado). Linguística Aplicada e Estudos da Linguagem. São Paulo, Pontifícia Universidade Católica de São Paulo, 2012.

MARTINS, Francine Cantarelli. Terminologia da Libras: coleta e registro de sinais-termo da área de psicologia. Tese (Doutorado). Programa de Pós-Graduação em Linguística. Universidade Federal de Santa Catarina, Florianópolis, 2018.

NASCIMENTO, Cristiane Batista do. Terminografia Língua de Sinais Brasileira: proposta de glossário ilustrado semibilíngue do meio ambiente, em mídia digital. Tese (Doutorado em Linguística) - Universidade de Brasília, Brasília, 2016.

NEMBRI, Armando Guimarães. O cotidiano escolar do Curso Bilíngue de Pedagogia do Instituto Nacional de Educação de Surdos - INES: um olhar avaliativo. Dissertação (Mestrado). Programa de Pós-Graduação da Fundação Cesgranrio, Fundação Cesgranrio, Rio de Janeiro, 2011.

NÓBREGA, Josley Maycon de Sousa. Proposta de um glossário de Libras para o curso de educação física/PARFOR-Patos, Paraíba. In: Congresso Nacional de Educação, 2017, João Pessoa. Anais IV CONEDU, 2017. v. 1. Disponível em:

https://www.editorarealize.com.br/index.php/artigo/visualizar/38415. Acesso em: 25. fev. 2021.

NORONHA, Daisy Pires; FERREIRA, Sueli Mara S. P. Revisões de literatura. In: CAMPELLO, Bernadete Santos; CONDÓN, Beatriz Valadares; KREMER, Jeannette Marguerite (orgs.) Fontes de informação para pesquisadores e profissionais. Belo Horizonte: UFMG, 2000.

OLIVEIRA, Janine Soares de. Análise descritiva da estrutura querológica de unidades terminológicas do glossário letras-libras. Tese (Doutorado) - Programa de PósGraduação em Estudos da Tradução, Universidade Federal de Santa Catarina.

Florianópolis, 2015.

QUADROS, Ronice Müller de.; STUMPF, Marianne Rossi. Letras Libras EaD. In: QUADROS, R. M (Org.). Letras LIBRAS: ontem, hoje e amanhã. Florianópolis: Editora UFSC, 2014, p. 9-36. 
RIBEIRO, Daniela Prometi. Glossário bilíngue da língua de sinais brasileira: Criação de sinais dos termos da música. Dissertação de Mestrado. Programa de Pós-Graduação em Linguística, Universidade de Brasília, Brasília, 2013.

SANTOS, Angélica Niero Mendes dos. A língua brasileira de sinais na educação de surdos: língua de instrução e disciplina curricular. Dissertação (Mestrado). Faculdade de Educação. São Paulo, Universidade de São Paulo. 2018.

TUXI, Patrícia. A terminologia na língua de sinais brasileira: proposta de organização e de registro de termos técnicos e administrativos do meio acadêmico em glossário bilíngue. Tese de Doutorado. Programa de Pós-Graduação em Linguística, Universidade de Brasília, Brasília, 2017.

VIEIRA, Claudia Regina. Educação bilíngue para surdos: reflexões a partir de uma experiência pedagógica. Tese (Doutorado). Faculdade de Educação, São Paulo, Universidade de São Paulo, 2017.

(c) (1) $(9$

This work is licensed under a Creative Commons Attribution-NonCommercial 4.0 International (CC BY-NC 4.0) 